\title{
Investigation of Supporting Electrolyte Effect on Supercapacitor Properties of Poly(Carbazole) Films
}

\author{
Berrin Duran*, İrem Çakmakcı Ünver, and Gözen Bereket \\ Eskişehir Osmangazi University, Faculty of Science and Letters, Department of Chemistry, 26480, Eskişehir, Turkey.
}

\begin{abstract}
In this study poly(carbazole) films deposited on stainless steel have been investigated as electrode material for supercapacitor applications. Poly(carbazole) films were electrodeposited using cyclic voltammetry in presence of lithium, sodium and tetrabutylammonium perchlorate salts. Poly(carbazole) films doped with perchlorate anions having different counter cations were characterized by SEM, ATR-FTIR and solid state conductivity measurements. Capacitive behaviours of PCz coated steel electrodes were tested by cyclic voltammetry, charge-discharge analysis and electrochemical impedance spectroscopy. It was found that counter cation of the dopant is significantly effective on the capacitive performance on the obtained PCz films and the PCz film synthesized from lithium perchlorate has the better capacitive performance than the poly(carbazole)s synthesized from sodium perchlorate and tetrabutylammonium perchlorate salts.
\end{abstract}

Keywords : Electropolymerization, Polycarbazole, Cyclic Voltammetry, EIS

Received : 18 April 2019, Accepted : 5 August 2019

\section{Introduction}

Electrochemical capacitors often called as supercapacitors and they are currently investigated due to their interesting characteristics in terms of power and energy densities. Supercapacitors find usage in portable electronics, buckup power supply and large-scale industrial power and energy management and these capacitors employ both aqueous and non-aqueous electrolytes [1-7]. Depending on the charge storage mechanism an electrochemical capacitor is classified as an electrical double layer capacitor or a pseudo capacitor. Double layer capacitors, store the energy by the ionic charges separation at the interface between electrode materials and the electrolyte. Pseudo capacitors store the energy by the fast and reversible faradaic reactions occurring within the active materials of electrode [8-10] and a pseudo capacitor typically stores a greater amount of capacitance per gram than an electrical double layer capaci-

*E-mail address: bduran@ogu.edu.tr

DOI: https://doi.org/10.33961/jecst.2019.00129

This is an open-access article distributed under the terms of the Creative Commons Attribution Non-Commercial License (http://creativecommons.org/licenses/by-nc/4.0) which permits unrestricted non-commercial use, distribution, and reproduction in any medium, provided the original work is properly cited. tor, as the bulk of the material (not just the surface layer) reacts [11].

Carbon based materials (carbon nanotubes, carbon nanofibers, graphenes, active carbon) are widely used as electrode active material in electrical double layer capacitors because of their porous structure, high surface area and high stability in charge/discharge. However, their low specific capacitances restrict the application of these materials. Transition metal oxides $\left(\mathrm{RuO}_{2}, \mathrm{~V}_{2} \mathrm{O}_{5}, \mathrm{SnO}_{2}, \mathrm{MnO}_{2}, \mathrm{NiO}\right)$ and electrically conducting polymers are mainly used as electrode materials in pseudo capacitors. Conducting polymers represent a promising class of active material class for pseudo capacitors because of their good electrical conductivity, large specific capacitance, easy synthesis and low cost compared to expensive and toxic metal oxides; although, they suffer from poor cycling stability during long charge/discharge processes [1,3,8,12-15].

The $\pi$-conjugated double bonds in the backbone of the conducting polymers transfer electrical charge from the current collector to the electrolyte $[1,16]$. The physical and electronic properties of a conducting polymer, such as surface morphology, thickness, doping anion, electrical conductivity, internal resistance and durability, directly affect the supercapacitor 
performance. Hence, great majority of researchers have paid attention to develop new and more effective polymeric electrode materials possessing unique electrochemical and morphological features [17].

Poly(aniline), poly(thiophene), poly(ethylenedioxythiophene) and poly(pyrrole) have been studied extensively for supercapacitor applications [18-30]. Among them, poly(pyrrole) (PPy) and its derivatives have been considered promising materials in energy storage applications due to advantages of facile synthesis, low cost and environmentally friendliness and high capacitance [3,31-33]. The capacitive performance of the polymer can be affected by the type, size and valance of the ions in preparing and testing solutions and it was found in literature that PPy doped with perchlorate anions presented more ideal supercapacitor properties than that of nitrate doped PPy [31,34-35].

The aim of this paper is a preliminary comparison of the capacitive performances of the same polymer synthesized from different supporting electrolytes. Carbazole $(\mathrm{Cz})$ is selected as monomer from the pyrrole family. Apart from the doping anion, effect of counter cation of dopant on the capacitive performance of the deposited film was discussed for the first time to the best of our knowledge. Capacitive performances of the poly(carbazole) $(\mathrm{PCz})$ coatings deposited from lithium perchlorate (LP), sodium perchlorate (SP) and tetrabutylammonium perchlorate (TBAP) electrolytes were examined in monomer free solution.

\section{Experimental}

\subsection{Materials}

Carbazole ( $\mathrm{Cz}, 95 \%)$, acetonitrile (ACN, 99.9\%), lithium perchlorate (LP, 99.9\%), sodium perchlorate (SP, 98\%), tetrabutylammonium perchlorate (TBAP, 99\%) and other chemicals used in this study were purchased from Sigma-Aldrich Chemicals. Platinum sheet (99.99\%) and Ag wire (99.98\%) were also supplied from Aldrich whereas 304 stainless steel (SS) rods were obtained locally.

The conventional three electrode system was used for all electrochemical experiments. 304 type stainless steel foils were cut into $1 \mathrm{~cm}^{2}$ area (1 mm thickness) and these foils were employed as working electrode. Before electropolymerization, the working electrode was ultrasonicated in acetonitrile and freshly used. Platinum sheet with $2 \mathrm{~cm}^{2}$ surface area and $\mathrm{Ag}$ wire were used as counter and pseudo reference electrode, respectively. The temperature was maintained at $25^{\circ} \mathrm{C}$.

\subsection{Equipments and instrumentation}

Electropolymerization and supercapacitor tests were carried out using a computer controlled Gamry Reference 600 potentiostat/galvanostat/ZRA system with Gamry Framework/Echem Analyst (Version 5.50) software. Microstructures of the polymer coated stainless steel surfaces were investigated via Jeol-JSM 5600LV model scanning electron microscope (SEM). FTIR spectra of the PCz coated steel samples were recorded by Perkin Elmer/Spectrum 100 ATR-FTIR spectrometer in the range of 400 to $4000 \mathrm{~cm}^{-1}$ with spectral resolution of $4 \mathrm{~cm}^{-1}$. Conductivity measurements of the polymer coated samples were conducted by means of conventional four-probe method (Keithley 2400 multimeter). The mass of the polymer films were measured by weighing the steel samples before and after polymerization samples using a digital balance with a sensitivity of $0.01 \mathrm{mg}$.

\subsection{Coating}

$\mathrm{Cz}$ monomer $(0.01 \mathrm{M})$ in $0.1 \mathrm{M}$ supporting electrolyte (LP, SP or TBAP) containing ACN solution was used for the polymer growth. The same synthesis parameters (potential range, scan rate and cycle number) were applied for the electropolymerization of $\mathrm{Cz}$ in order to find out the effect of the supporting electrolyte on the supercapacitor performance of the deposited polymer. The PCz films were electrochemically synthesized by cyclic continuously the electrode potential between $+0.3 \mathrm{~V}$ and $+1.4 \mathrm{~V}$ (vs Ag) at $50 \mathrm{mV} / \mathrm{s}$ scan rate by applying 10 cycles and adherent $\mathrm{PCz}$ films were obtained on SS surface using fresh solutions. Followed by the growth, polymer coated electrodes $(\mathrm{SS} / \mathrm{PCz})$ were rinsed with $\mathrm{ACN}$ and dried prior to electrochemical evaluation of specific capacitance in monomer free solution.

\subsection{Supercapacitive performance}

Capacitive behavior of the $\mathrm{PCz}(\mathrm{LP}), \mathrm{PCz}(\mathrm{SP})$ and $\mathrm{PCz}(\mathrm{TBAP})$ coated steel electrodes were investigated in $0.1 \mathrm{M}$ perchlorate salt containing acetonitrile (monomer free) solution by repeating chronopotentiometry (RCP), cyclic voltammetry (CV) and electrochemical impedance spectroscopy (EIS) techniques. 
Charge-discharge curves were recorded using repeating chronoamperometry technique at $1 \mathrm{~mA} / \mathrm{cm}^{2}$ constant current density and voltage range of the SS/ $\mathrm{PCz}(\mathrm{LP}), \mathrm{SS} / \mathrm{PCz}(\mathrm{SP})$ and $\mathrm{SS} / \mathrm{PCz}$ (TBAP) electrodes were determined by this technique. Charge-discharge stabilities of the electrodes were tested by 500 consecutive cycles using repeating chronopotentiometry method. Different scan rates $(5,10,15,20 \mathrm{mV} / \mathrm{s})$ were applied by cyclic voltammetry in order to determine scan rate dependence of the deposited materials. Impedance measurements were carried out at open circuit potential with the ac amplitude of $10 \mathrm{mV}$ within the frequency range of $100 \mathrm{kHz}-10 \mathrm{mHz}$ after the electrodes were allowed to stabilize in the test solution for 30 minutes.

\section{Results and Discussion}

\subsection{Electrochemical synthesis of $\mathrm{PCz}$ films}

$\mathrm{PCz}(\mathrm{LP}), \mathrm{PCz}(\mathrm{SP})$ and $\mathrm{PCz}(\mathrm{TBAP})$ films were electrochemically synthesized on SS electrode in $0.01 \mathrm{M} \mathrm{Cz}+0.1 \mathrm{M}$ lithium perchlorate (LP), $0.01 \mathrm{M}$ $\mathrm{Cz}+0.1 \mathrm{M}$ sodium perchlorate (SP) and $0.01 \mathrm{M} \mathrm{Cz}+$ $0.1 \mathrm{M}$ tetrabutylammonium perchlorate (TBAP) containing acetonitrile (ACN) solutions, respectively. Synthesis were performed by using cyclic voltammetry in the potential range between $+0.3 \mathrm{~V}$ and $+1.4 \mathrm{~V}$ at $50 \mathrm{mV} / \mathrm{s}$ scan rate for 10 cycles. Fig. 1 shows cyclic voltammograms recorded during electropolymerization of $\mathrm{Cz}$ monomer from LP, SP and TBAP supporting electrolytes on the SS surface. In these voltammograms, peaks observed at $+1.20 \mathrm{~V}$ in the first forward scans belong to oxidation of the $\mathrm{Cz}$ monomer. Formation of $\mathrm{PCz}$ films on the SS surface starts with this oxidation. The intensity of the oxidation peaks gradually increase with subsequent scans. Reduction of the PCz films can be seen from the first reverse scans approximately at $+0.9 \mathrm{~V}$ potential; whereas the oxidation of $\mathrm{PCz}$ films can be seen from the second forward scans at around $+0.8 \mathrm{~V}$. These broad peaks also increase gradually due to the polymer growth on the SS surfaces. At the end of 10 cycles, dark green coloured and homogeneous $\mathrm{PCz}$ films were observed on the steel surface, in all cases.

\subsection{Characterization of PCz films}

Conductivity of the $\mathrm{SS} / \mathrm{PCz}(\mathrm{LP}), \mathrm{SS} / \mathrm{PCz}(\mathrm{SP})$ and $\mathrm{SS} / \mathrm{PCz}(\mathrm{TBAP})$ electrodes were measured as $1 \times 10^{-4}$, $6.7 \times 10^{-5}$ and $1.3 \times 10^{-5} \mathrm{~S} / \mathrm{cm}$, respectively. It is clear
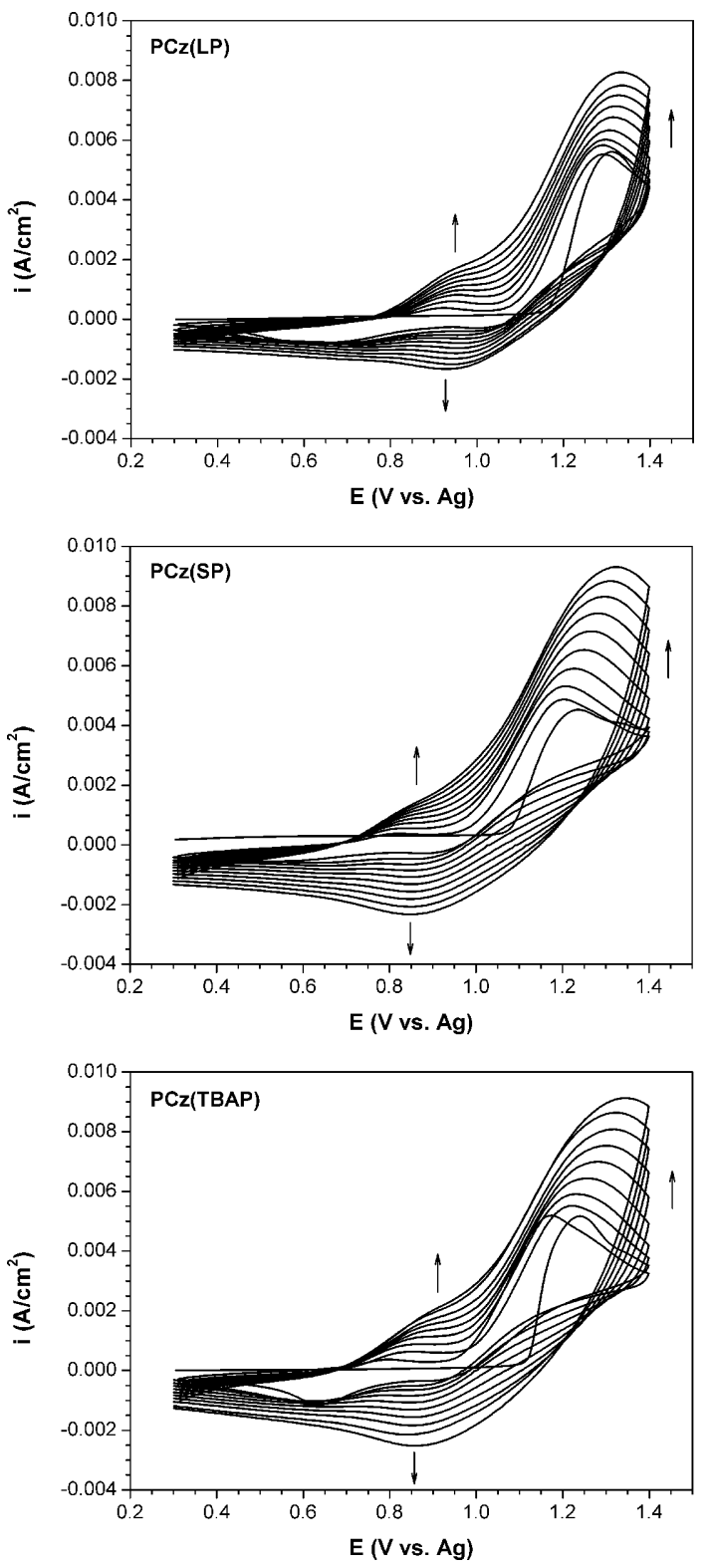

Fig. 1. Potentiodynamic deposition of $\mathrm{PCz}$ films from acetonitrile solutions containing different supporting electrolytes (LP, SP and TBAP) on 304 type SS.

from these values that the supporting electrolyte is effective on the conductivity of the synthesized polymer even if the same synthesis parameters were applied. Conductivities of the $\mathrm{PCz}$ films decreased in the order of $\mathrm{PCz}(\mathrm{LP})>\mathrm{PCz}(\mathrm{SP})>\mathrm{PCz}(\mathrm{TBAP})$. This order might be correlated with the size of the counter cation of the dopant entered into the polymer matrix 
and it can be inferred that larger cations reduce the conductivity of the polymer film [36,37].

Fig. 2 shows the ATR-FTIR spectra of the PCz coatings synthesized on steel electrodes. Similar characteristic bands of the PCz coatings show that all the deposited films have the same chemical structure. Peaks appeared at $1072-1092 \mathrm{~cm}^{-1}$ assigned to stretching vibrations of $\mathrm{C}-\mathrm{N}$ bonds in $\mathrm{PCz}$ and these broad bands are indication of polymer formation. Peaks at $1400-1600 \mathrm{~cm}^{-1}$ are contributed to the stretching vibrations of aromatic rings in $\mathrm{PCz}$ units. Peaks at 680-685 are arisen from the adsorption of perchlorate doping anions [38]. The typical broad adsorption of organic conductors in the region above $2000 \mathrm{~cm}^{-1}$ hinders the detection of the $3567 \mathrm{~cm}^{-1} \mathrm{~N}-\mathrm{H}$ stretching band [36].

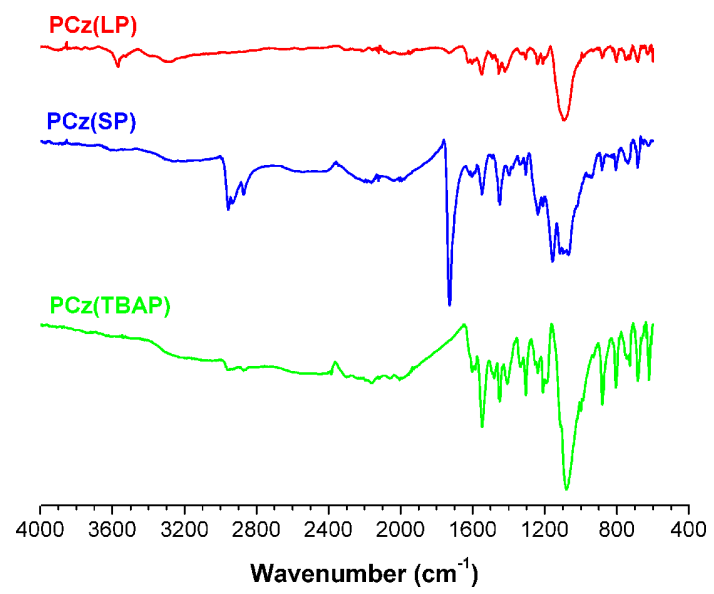

Fig. 2. ATR-FTIR spectra of PCz films deposited on SS.

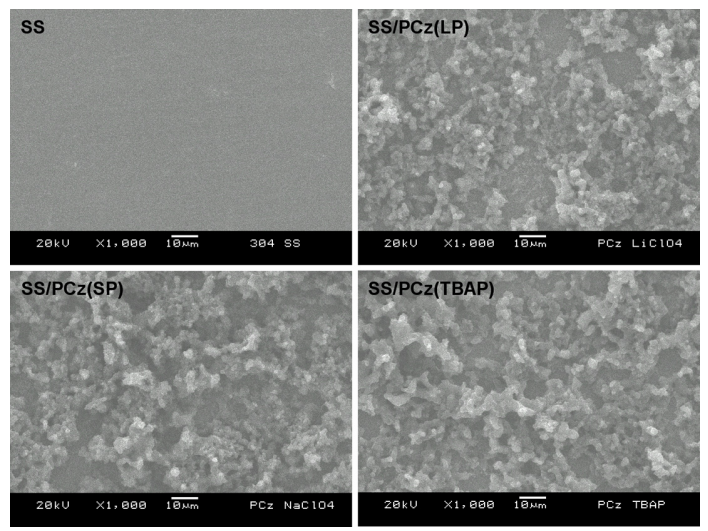

Fig. 3. SEM images of bare and PCz coated steel surfaces.
Fig. 3 shows SEM images of uncoated and $\mathrm{PCz}$ coated SS samples. As seen from the SEM profiles, all the $\mathrm{PCz}$ coatings exhibit very similar grain structures. Difference of the micrographs of the SS/PCz samples is particle size and density. Fig. 3 clearly shows that size of the polymer grains was affected by the type of the supporting electrolyte and particle size can be correlated with the size of counter cation of the dopant. In parallel, small particle size means higher surface area. In this respect $\mathrm{PCz}(\mathrm{LP})$ has maximum surface area compared to $\mathrm{PCz}(\mathrm{SP})$ and $\mathrm{PCz}(\mathrm{TBAP})$, hence expected to exhibit higher capacitance values, which indeed observed.

\subsection{Capacitive performances of the $\mathrm{PCz}$ films}

In order to see the potential application of the $\mathrm{PCz}(\mathrm{LP}), \mathrm{PCz}(\mathrm{SP})$ and $\mathrm{PCz}(\mathrm{TBAP})$ coated steel electrodes in supercapacitors, galvanostatic tests, cyclic voltammetry and electrochemical impedance spectroscopy have been used and specific capacitance values of the electrodes have been calculated for each technique used.

Electrochemical response of the $\mathrm{SS} / \mathrm{PCz}(\mathrm{LP}), \mathrm{SS} /$ $\mathrm{PCz}(\mathrm{SP})$ and $\mathrm{SS} / \mathrm{PCz}(\mathrm{TBAP})$ electrodes have been determined by galvanostatic tests as the first step. Charge-discharge profiles of the $\mathrm{PCz}$ coated samples were given in Fig. 4 for the first 10 cycles. All of the curves recorded at $1 \mathrm{~mA} / \mathrm{cm}^{2}$ constant current density exhibited triangle-like curves as expected charge-discharge behavior for an ideal supercapacitor. From the figure, it can be seen that the initial voltage drop during charge-discharge is smaller for $\mathrm{SS} / \mathrm{PCz}(\mathrm{LP})$ than the $\mathrm{SS} / \mathrm{PCz}(\mathrm{SP})$ and SS/PCz(TBAP). The difference between ohmic drops means that $\mathrm{SS} / \mathrm{PCz}(\mathrm{LP})$ has a better supercapacitive behavior than the other samples. Specific capacitances $\left(\mathrm{C}_{\mathrm{sp}}\right)$ of the electrodes were calculated by Equation 1 given below using the galvanostatic charge-discharge curves and given in Table 1.

$$
C_{s p}=\frac{i \times t_{d}}{\Delta V \times m}
$$

where $\mathrm{C}_{\mathrm{sp}}$ is the specific capacitance $(\mathrm{F} / \mathrm{g}), \mathrm{i}$ is the discharge current $\left(\mathrm{mA} / \mathrm{cm}^{2}\right), t_{\mathrm{d}}$ is the discharge time (s), $\Delta \mathrm{V}$ is the potential difference in the discharge process $(\mathrm{V})$ and $\mathrm{m}$ is the mass of the active material (mg). $\mathrm{PCz}(\mathrm{LP})$ electrode has the specific capacitance about $118 \mathrm{~F} / \mathrm{g}$ at the early stage of cycling while $\mathrm{PCz}(\mathrm{SP})$ and $\mathrm{PCz}(\mathrm{TBAP})$ has 64 and $21 \mathrm{~F} / \mathrm{g}$. It is 
Table 1. Specific capacitance values obtained from electrochemical tests of $\mathrm{SS} / \mathrm{PCz}(\mathrm{LP}), \mathrm{SS} / \mathrm{PCz}(\mathrm{SP})$ and $\mathrm{SS} /$ $\mathrm{PCz}$ (TBAP) electrodes in monomer free solutions.

\begin{tabular}{cccc}
\hline \hline Electrode & $\begin{array}{c}\text { Csp (F/g) } \\
\text { (Charge-Discharge) }\end{array}$ & $\begin{array}{c}\text { Csp(F/g) } \\
\text { (CV) }\end{array}$ & $\begin{array}{c}\text { Csp (F/g) } \\
\text { (EIS) }\end{array}$ \\
\hline $\mathrm{SS} / \mathrm{PCz}(\mathrm{LP})$ & 118 & 114 & 133 \\
$\mathrm{SS} / \mathrm{PCz}(\mathrm{SP})$ & 64 & 60 & 64 \\
$\mathrm{SS} / \mathrm{PCz}(\mathrm{TBAP})$ & 21 & 16 & 9 \\
\hline
\end{tabular}
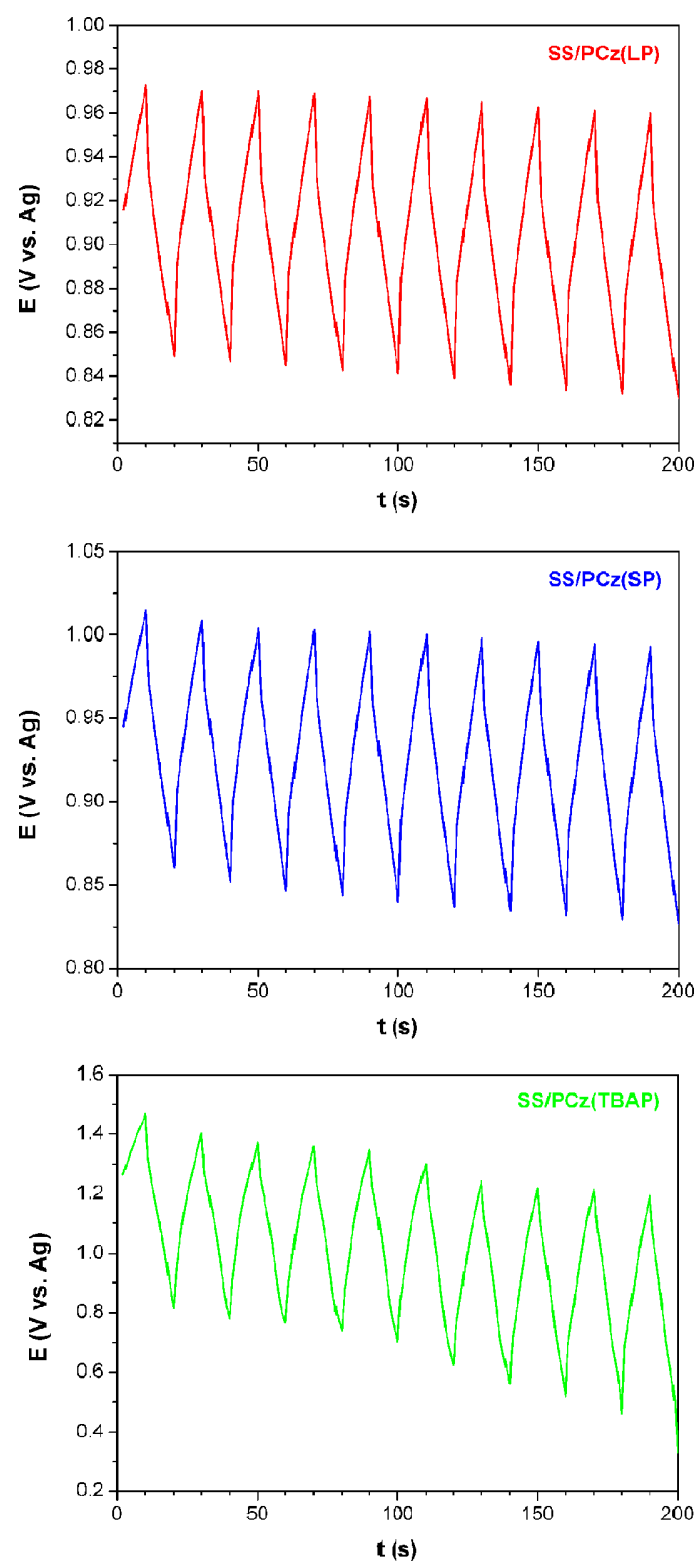

Fig. 4. Charge-discharge behaviors of the SS/PCz electrodes for the first 10 cycles in their monomer free solutions. probably due to that the degradation of $\mathrm{PCz}$ polymer is higher in the presence of SP and TBAP in the polymer matrix.

Cyclic voltammetry (CV) is an effective method to reveal the capacitive behavior of the electrodes and $\mathrm{CV}$ studies were performed by means of different scan rates as second step. 5, 10, 15 and $20 \mathrm{mV} / \mathrm{s}$ scan rates were applied to electrodes in the optimum
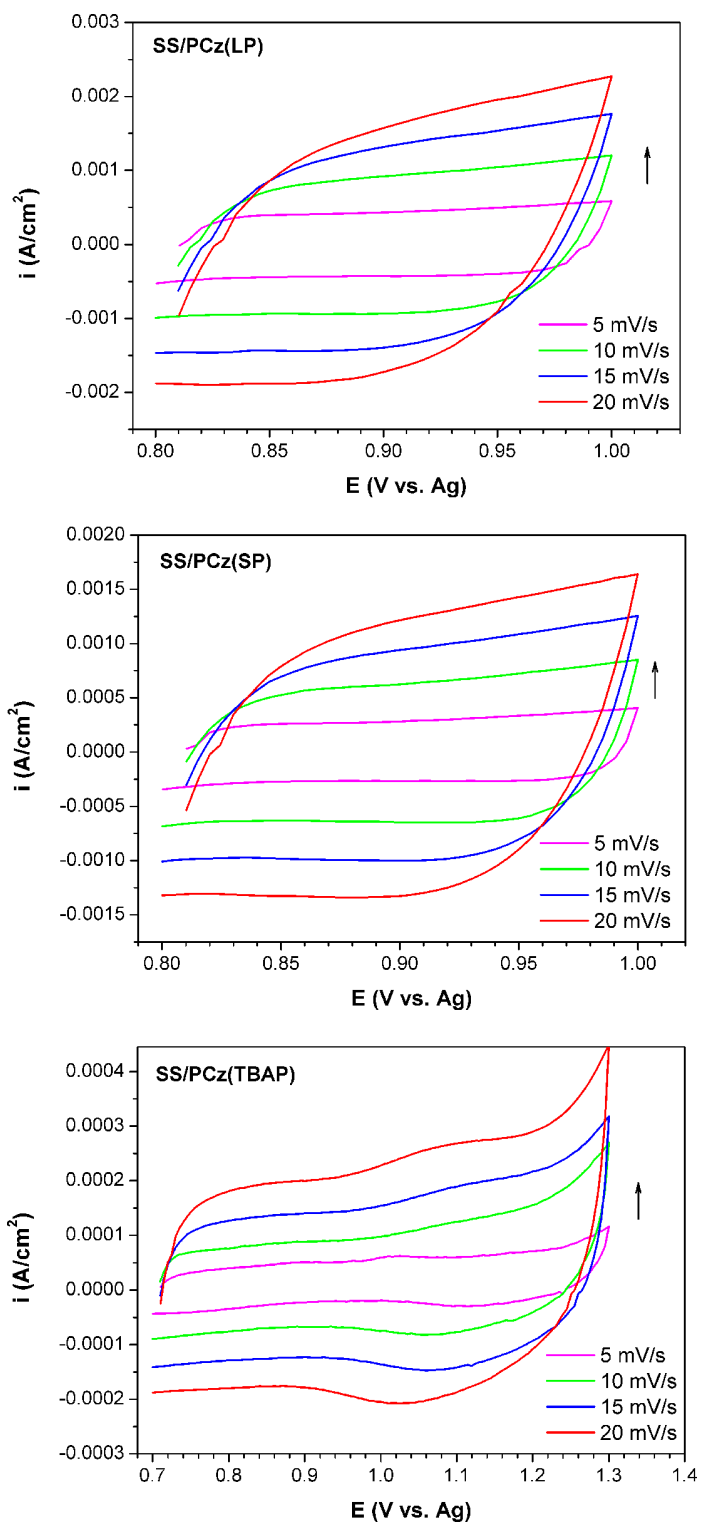

Fig. 5. $\mathrm{CV}$ curves of $\mathrm{SS} / \mathrm{PCz}$ electrodes at different scan rates in their monomer free solutions. 
potential window determined from the charge-discharge curves of the each electrode. Scan rates higher than $20 \mathrm{mV} / \mathrm{s}$ were not given here due to deviations from rectangular shape were started. There are similar studies in literature that low scan rates have been applied [39]. Fig. 5 shows cyclic voltammograms recorded for SS/PCz(LP), SS/PCz(SP) and SS/ $\mathrm{PCz}(\mathrm{TBAP})$ electrodes in monomer free solution. Rectangular shaped curves observed for all electrodes and current increased with increase of scan rate. It is reported that rectangular shaped $\mathrm{CV}$ is typical for pseudo supercapacitors [40,41]. PCz films synthesized from LP, SP and TBAP show capacitivelike responses and current increases with scan rate. Comparing $\mathrm{CV}$ areas of the SS/PCz(LP), SS/ $\mathrm{PCz}(\mathrm{SP})$ and $\mathrm{SS} / \mathrm{PCz}(\mathrm{TBAP})$ electrodes we can find that the specific capacitance of $\mathrm{SS} / \mathrm{PCz}(\mathrm{LP})$ is greater than $\mathrm{SS} / \mathrm{PCz}(\mathrm{SP})$ and $\mathrm{SS} / \mathrm{PCz}(\mathrm{TBAP})$ electrodes [42]. Quantitative specific capacitances were calculated by the Equation (2) using cyclic voltammetry curves (for $20 \mathrm{mV} / \mathrm{s}$ scan rate) and listed in Table 1.

$$
C_{s p}=\frac{i}{m \times(d V / d t)}
$$

where $i$ is the peak current $\left(\mathrm{mA} / \mathrm{cm}^{2}\right), \mathrm{m}$ is the mass of the active material $(\mathrm{mg})$ and $\mathrm{dV} / \mathrm{dt}$ is the scan rate (V/s). $\mathrm{PCz}(\mathrm{LP})$ electrode has $114 \mathrm{~F} / \mathrm{g}$ specific capacitance while $\mathrm{PCz}(\mathrm{SP})$ and $\mathrm{PCz}(\mathrm{TBAP})$ has 60 and $16 \mathrm{~F} /$ $\mathrm{g}$, respectively. The results obtained from galvanostatic tests and cyclic voltammetry support each other.

As third step, EIS has been utilized to obtain information about the frequency response of the electrodes suggested as electrode active materials for supercapacitor applications. The Nyquist diagrams obtained from the EIS measurements were given in Fig. 6. These diagrams are composed of a semicircle at high frequency and a straight line in the low frequency region. The semicircle at high frequency represents the charge transfer process at electrode/ electrolyte interface while the straight line at low frequency is characteristics of diffusion limiting step electrochemical process. From the Nyquist diagrams electrochemical storage properties of these electrodes are based on both electrical double layer and faradaic process. Low charge transfer resistance at the high frequency region is attributed to fast charge transfer between polymer and the metal. Therefore obtained specific capacitance value is to be highly small at that frequency and so, it is impossible to expect ideal
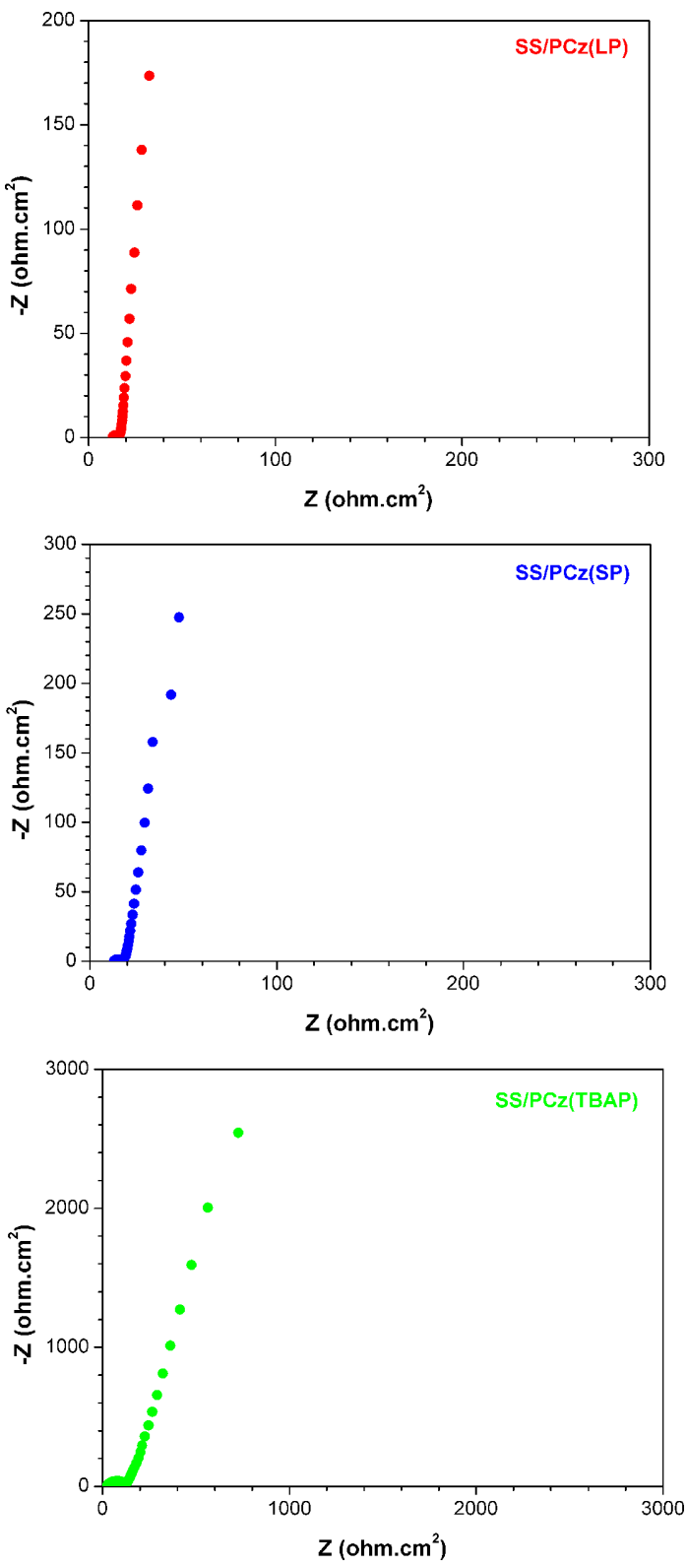

Fig. 6. EIS spectra of SS/PCz electrodes in their monomer free solutions.

capacitor behaviour. On the other hand at low frequency region, charge transfer is very slow. This means that charge transfer occurring on the metal surface and the electrode behaves as an ideal capacitor [40]. The specific capacitance values of the SS/ $\mathrm{PCz}(\mathrm{LP}), \mathrm{SS} / \mathrm{PCz}(\mathrm{SP})$ and $\mathrm{SS} / \mathrm{PCz}(\mathrm{TBAP})$ electrodes were calculated using the imaginary part of the EIS 
spectra from the low frequency $\left(10^{-2} \mathrm{~Hz}\right)$ data by using the Equation (3).

$$
C_{s p}=-\frac{1}{2 \pi f m Z_{i m}}
$$

where $\mathrm{C}_{\mathrm{sp}}$ is the specific capacitance $(\mathrm{F} / \mathrm{g}), \mathrm{f}$ is the frequency $(\mathrm{Hz}), \mathrm{m}$ is the mass of the active material (g) and $Z_{\text {im }}$ is the imaginary impedance (ohms) and the results were shown in Table 1. 133, 64 and $9 \mathrm{~F} / \mathrm{g}$ specific capacitance values calculated for $\mathrm{SS} /$ $\mathrm{PCz}(\mathrm{LP}), \mathrm{SS} / \mathrm{PCz}(\mathrm{SP})$ and SS/PCz(TBAP) electrodes, respectively. All the calculated specific capacitance values follow the same trend and $\mathrm{C}_{\mathrm{sp}}$ values can be ordered as $\mathrm{PCz}(\mathrm{LP})>\mathrm{PCz}(\mathrm{SP})>\mathrm{PCz}(\mathrm{TBAP})$ for each of the electrochemical test technique used. Table 1 summarizes that $\mathrm{C}_{\mathrm{sp}}$ values obtained from $\mathrm{RCP}, \mathrm{CV}$ and EIS techniques are in good agreement.

It has been reported in literature that pseudocapacitors produced by conducting polymers showed average specific capacitance values in the range of 100200 F/g [1,11,43-49]. Accordingly, the only PCz(LP) can be considered as the active electrode material for supercapacitor application. Low specific capacitances of the $\mathrm{PCz}(\mathrm{SP})$ and $\mathrm{PCz}(\mathrm{TBAP})$ can be attributed to relatively big size of counter ions, big particle size in their morphologic structures and also relatively low conductivity of these materials. As it is known, the electrode capacitance depends on the morphology, porous structure and conductivity. Large counter ions (sodium and tetrabutylammonium) have restricted mobility and low mobility results in restricted doping-dedoping and lower electrical conductivity [50,51]. Furthermore, tiny particle size increases surface area as well as specific capacitance, while low conductivity causes decrease in specific capacitance of the material. SEM and conductivity investigations show that decrease in specific capacitance can be attributed to increasing particle size, decreasing film porosity and low conductivity of $\mathrm{PCz}(\mathrm{SP})$ and $\mathrm{PCz}$ (TBAP). Nevertheless, obtained results clearly reveal that charge-discharge profiles and EIS and also CV studies are in good agreement.

In literature it has been stated that when carbon fiber micro electrode (CFME) was coated by $\mathrm{PCz}$ in $\mathrm{LiClO}_{4}$ containing ACN solution ( $\mathrm{LP} / \mathrm{ACN}$ ), $\mathrm{C}_{\mathrm{sp}}$ value of CFME/PCz has been calculated as $280.5 \mathrm{mF} / \mathrm{g}$ in monomer free solution according to EIS data. Similarly, $\mathrm{C}_{\mathrm{sp}}$ value of the CFME/PCz electrode has been calculated as $29.7 \mathrm{mF} / \mathrm{g}$ in tetra ethyl ammonium per-
Table 2. Comparison of $\mathrm{C}_{\mathrm{sp}}$ values obtained from EIS data for $\mathrm{SS} / \mathrm{PCz}$ and $\mathrm{CFME} / \mathrm{PCz}$ electrodes in acetonitrile solution containing different supporting electrolytes (lithium perchlorate, tetrabuthyl ammonium perchlorate and tetraethyl ammonium perchlorate).

\begin{tabular}{cc}
\hline \hline Electrode & $\mathrm{C}_{\mathrm{sp}}(\mathrm{F} / \mathrm{g})$ \\
calculated from EIS data \\
\hline $\mathrm{SS} / \mathrm{PCz}(\mathrm{LP})$ & 133 \\
$\mathrm{SS} / \mathrm{PCz}(\mathrm{TBAP})$ & 9 \\
${ }^{*} \mathrm{CFME} / \mathrm{PCz}(\mathrm{LP})$ & 0.2805 \\
${ }^{*} \mathrm{CFME} / \mathrm{PCz}(\mathrm{TEAP})$ & 0.0297 \\
\hline
\end{tabular}

"Results were taken from literature [52] for comparison of $\mathrm{C}_{\mathrm{sp}}$ values of the same material $(\mathrm{PCz})$ on different substrates ( $\mathrm{SS}$ and CFME).

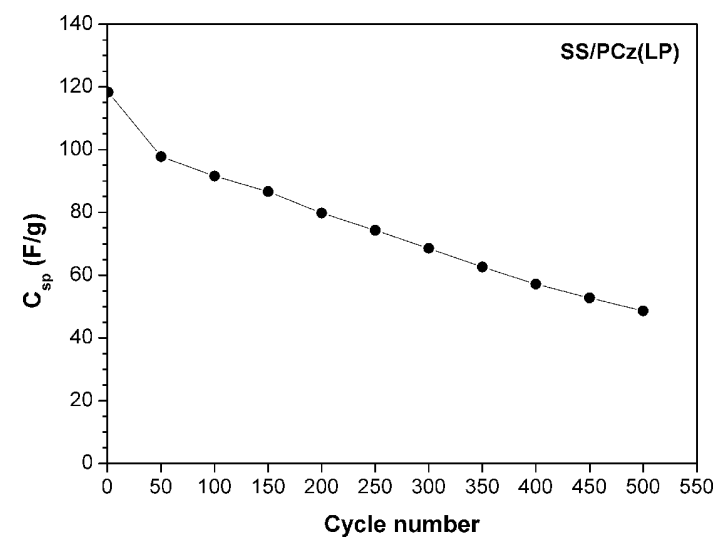

Fig. 7. Cycling performance of $\mathrm{SS} / \mathrm{PCz}(\mathrm{LP})$ electrode in monomer free solution.

chlorate (TEAP) containing acetonitrile solution (TEAP/ACN) [52]. These $\mathrm{C}_{\mathrm{sp}}$ values were given in Table 2 for comparison. Table 2 reveals that $\mathrm{C}_{\mathrm{sp}}$ values of SS/PCz are higher than that of CFME/PCz and substrate also effective on specific capacitance of the material. Additionally, we can infer from Table 2, higher $\mathrm{C}_{\mathrm{sp}}$ was obtained when LP was used as the supporting electrolyte for both electrodes $(\mathrm{SS} / \mathrm{PCz}$ and $\mathrm{CFME} / \mathrm{PCz}$ ).

The cycling stability of the $\mathrm{PCz}(\mathrm{LP})$ electrode against 500 charge-discharge cycles was also tested. Fig. 7 represents the variation of specific capacitance of the $\mathrm{PCz}(\mathrm{LP})$ with cycling. From the trend of this plot, we can say that there may be higher voltage drop with cycling because of decrease of dopingdedoping activity as well as degradation of $\mathrm{PCz}(\mathrm{LP})$ polymer. Charge-discharge efficiency was found as 
$59 \%$ according to the results obtained from chargedischarge curves. Deterioration rate of the $\mathrm{PCz}(\mathrm{LP})$ material might be reduced by addition of different additives to the polymer matrix and so increase in specific capacitance can be achieved.

\section{Conclusions}

* Pseudocapacitive performances of polycarbazole films deposited on stainless steel in presence of three different perchlorate salt (lithium, sodium and tetrabutyl ammonium perchlorate) have been investigated as electrode materials for supercapacitor applications.

* All the PCz films showed capacitive behaviour in monomer free solution and it was found that cation of dopant is considerably effective on the capacitive property of the produced $\mathrm{PCz}$ films.

* It is inferred that size of counter cation, morphological structure and conductivity affect capacitive performance of the coating.

* As a result, $\mathrm{PCz}(\mathrm{LP})$ was found to be more suitable as the electrode active material for electrochemical capacitor applications due to $\mathrm{PCz}(\mathrm{LP})$ has maximum specific capacitance among the others and performance of this material can be improved by addition of different modifiers.

\section{Acknowledgement}

The authors gratefully acknowledge the financial support of the Eskişehir Osmangazi University Scientific Research Fund (Project No: 201119038).

\section{References}

[1] D. Kalpana, Y.S. Lee, Y. Sato, J. Power Sources, 2009, 190(2), 592-595.

[2] M.S. Kumar, D.K. Bhat, Physica B, 2009, 404(8-11), 1143-1147.

[3] B.E. Conway, Electrochemical Supercapacitors, Scientific Fundamentals and Technology Applications, Kluwer Academic Publishers, Plenum Press, New York, 1999.

[4] E. Hür, A. Arslan, Synth. Met., 2014, 193, 81-88.

[5] J.R. Miller, P. Simon, Science, 2008, 321(5889), 651652.

[6] J.R. Miller, A.F. Burke, Electrochem. Soc. Interface, 2008, 17(1), 53-57.

[7] Z. Zhou, X.F. Wu, J. Power Sources, 2013, 222, 410416.
[8] M. Çağlar, A. Arslan, R. Kılıç, E. Hür, Synth. Met., 2015, 206, 8-14.

[9] L. Li, E .Liu, J. Li, Y. Yang, H. Shen, Z. Huang, X. Xiang, W. Li, J. Power Sources, 2010, 195(5), 15161521.

[10] M. Jin, G. Han, Y. Chang, H. Zhao, H. Zhang, Electrochim. Acta, 2011, 56(27), 9838-9845.

[11] G.A. Snook, P. Kao, A.S. Best, J. Power Sources, 2011, 196(1), 1-12.

[12] S. Sarangapani, B.V. Tilak, C.P. Chen, J. Electrochem. Soc., 1996, 143(11), 3791-3799.

[13] J.P. Zheng, T.R. Jow, J. Power Sources, 1996, 62(2), $155-159$.

[14] F. Cao, Y. Liu, B. Chen, L. Fei, Y. Wang, J. Yuan, Electrochim. Acta, 2012, 81, 1-7.

[15] H. Liu, Y. Wang, X. Gou, T. Qi, J. Yang, Y. Ding, Mater. Sci. Eng. B., 2013, 178(5), 293-298.

[16] Y. Shen, M. Wan, Synth. Met., 1998, 96(2), 127-132.

[17] D. Yiğit, M. Güllü, Electrochim. Acta, 2018, 282, 64-80.

[18] A. Eftekhari, L. Li, Y. Yang, J. Power Sources, 2017, 347, 86-107.

[19] P.Liu, J. Yan, Z. Guang, Y. Huang, X. Li, W. Huang, J. Power Sources, 2019, 424, 108-130.

[20] S. M. Selvakumar, Int. J. Hydrogen Energy, 2018, 43(8), 4067-4080.

[21] A. Laforgue, P. Simon, C. Sarrazin, J.F. Fauvarque, $J$. Power Sources, 1999, 80(1-2), 142-148.

[22] K. Wu, J. Zhao, R. Wu, B. Ruan, H. Liu, M. Wu, J. Electroanal. Chem., 2018, 823, 527-530.

[23] C. Fu, H. Zhou, R. Liu, Z. Huang, J. Chen, Y. Kuang, Mater. Chem. Phys., 2012, 132(2-3), 596-600.

[24] D.V. Zhuzhelskii, E.G. Tolstopjatova, S.N. Eliseeva, A.V. Ivanov, S. Miao, V.V. Kondratiev, Electrochim. Acta, 2019, 299, 182-190.

[25] B.M. Hryniewicz, H. Winnischofer, M. Vidotti, J. Electroanal. Chem., 2018, 823, 573-579.

[26] M. Suominen, P. Damlin, C. Kvarnström, Electrochim. Acta, 2019, 307, 214-223.

[27] A. Afzal, F.A. Abuilaiwi, A. Habib, M. Awais, S.B. Waje, M.A. Atieh, J. Power Sources, 2017, 352, 174186

[28] P. Atri, D.C. Tiwari, R. Sharma, Synth. Met., 2017, 227, 21-28.

[29] E. Karaca, D. Gökcen, N. Ö. Pekmez, K. Pekmez, Synth. Met., 2019, 247, 255-267.

[30] B.S. Singu, K.R. Yoon, J. Alloys Compd., 2018, 742, 610-618.

[31] W. Sun, X. Chen, J. Power Sources, 2009, 193(2), 924929.

[32] Y. Xu, J. Wang, W. Sun, S. Wang, , J. Power Sources, 2006, 159(1), 370-373.

[33] W.C. Chen, T.C. Wen, H. Teng, Electrochim. Acta, 2003, 48(6), 641-649.

[34] C. Weidlich, K.M. Mangold, K. Jüttner, Electrochim. Acta, 2005, 50(7-8), 1547-1552.

[35] S.H. Song, D.S. Han, H.J. Lee, H.S. Cho, S.M. Chang, 
J.M. Kim, H. Muramatsu, Synth. Met., 2001, 117(1-3), 137-139.

[36] B. Duran, İ.Çakmakcı, G. Bereket, Corros. Sci., 2013, 77, 194-201.

[37] A.S. Saraç, M. Ateş, E.A. Parlak, J. Appl. Electrochem., 2006, 36(8), 889-898.

[38] V. Raj, D. Madheswari, M.M. Ali, J. Appl. Polym. Sci., 2010, 116(1), 147-154.

[39] V.S. Jamadede, D.S. Dhawale, C.D. Lokhande, Synth. Met., 2010, 160(9-10), 955-960.

[40] M. Güllü, D. Yiğit, Synth. Met., 2012, 162(15-16), 14341442.

[41] C. Arbizzani, M. Mastragostino, L. Meneghello, Electrochim. Acta, 1996, 41(1), 21-26.

[42] J. Wang, Y. Xu, X. Chen, X. Du, J. Power Sources, 2007, 163(2), 1120-1125.

[43] E. Ermiş, D. Yiğit, M. Güllü, Electrochim. Acta, 2013, 90, 623-633.
[44] Y. Zhang, Z. Qin, Integr. Ferroelectr., 2011, 128(1), 8690.

[45] A. Rudge, I. Raistrick, S. Gottesfeld, J.P. Ferraris, Electrochim. Acta, 1994, 39, 273-287.

[46] B. Muthulakshmi, D. Kalpana, S. Pitchumani, N.G. Renganathan, J. Power Sources, 2006, 158(2), 15331537.

[47] C.C. Hu, C.H. Chu, J. Electroanal. Chem., 2001, 503(1), 105-116.

[48] P.R. Kumar, D. Kalpana, N.G. Renganathan, S. Pitchumani, Synth. Met., 2007, 157(22-23), 899-904.

[49] B. Wessling, Synth. Met., 1998, 93(2), 143-154.

[50] S. Chen, I. Zhitomirsky, Mater. Lett., 2013, 98, 67-70.

[51] G.R. Mitchell, F.J. Davis, C.H. Legge, Synth. Met., 1988, 26(3), 247-257.

[52] M. Ates, A.S. Saraç, J. Appl. Electrochem., 2009, 39(10), 2043-2048. 